\title{
Bulk carbonate and foraminiferal calcium isotope ratios indicate calcification stress preceded Oceanic Anoxic Event 2
}

\author{
GABRIELLA D. KITCH ${ }^{1}$, ANDREW D JACOBSON ${ }^{1}$, \\ RODOLFO COCCIONI ${ }^{2}$, TIA CHUNG-SWANSON ${ }^{1}$, \\ MATTHEW HURTGEN ${ }^{1}$ AND BRADLEY B SAGEMAN ${ }^{1}$ \\ ${ }^{1}$ Northwestern University \\ ${ }^{2}$ Università degli Studi di Urbino \\ Presenting Author: gabby@earth.northwestern.edu
}

Large and rapid injections of $\mathrm{CO}_{2}$ to the Earth's surface disrupt marine carbonate equilibria and cause ocean acidification (OA), resulting in calcification stress for many marine organisms. The calcium isotope composition $\left(\delta^{44 / 40} \mathrm{Ca}\right)$ of primary carbonate producers may be sensitive to $\mathrm{OA}$, as $\mathrm{Ca}$ isotopic offsets between seawater and calcite depend on precipitation rate. $\mathrm{CaCO}_{3}$ (wt \%) measurements on globally distributed sediments support OA-driven shoaling of the calcite compensation depth (CCD) just prior to Oceanic Anoxic Event 2 (OAE2; 94 Ma). Additionally, specimens of the planktic foraminifera Rotalipora cushmani, sampled from the classic Bottaccione section in Gubbio (central Italy), show morphological evidence for environmental stress in the lower critical interval (LCI) leading up to OAE2, here recorded by the Bonarelli Level. $R$. cushmani $\delta^{44 / 40} \mathrm{Ca}$ spanning the LCI increase from $-1.55 \%$ to $-1.40 \%$ (OSIL seawater scale), consistent with reduced carbonate precipitation rates. A paired bulk carbonate $\delta^{44 / 40} \mathrm{Ca}$ record also shows elevated $\delta^{44 / 40} \mathrm{Ca}$ in the LCI; however, small, but analytically resolvable, differences between the records suggest that organism-specific records may best capture changes in seawater chemistry. Comparing the $\delta^{44 / 40} \mathrm{Ca}$ records generated in this study to complementary records from the Western Interior Basin demonstrates globally consistent positive excursions. These geochemical and morphological indicators provide evidence that $R$. cushmani experienced OA-driven calcification stress prior to OAE2. Reduced calcification may have increased alkalinity and contributed to shoaling of the CCD. Increased $\mathrm{CO}_{2}$ emissions from eruptions of the Caribbean LIP and/or High Arctic LIP may have caused OA. 